\title{
FALSIFICACIÓN DE MONEDA EN CONVENTOS CORDOBESES EN 1661
}

\author{
POR \\ Javier de Santiago Fernández \\ Universidad Complutense
}

\begin{abstract}
Resumen
En el presente artículo se estudian diversos casos de falsificación de moneda de vellón acaecidos todos en diferentes conventos religiosos situados en la ciudad de Córdoba en los afios finales del reinado de Felipe IV. Es la moneda el eje del trabajo, núcleo central que permite profundizar en un aspecto de la vida de los religiosos del siglo XVII y en la problemática situación social, económica y jurisdiccional que les Ilevó a falsificar moneda, apoyados por diversos integrantes de la sociedad civil.
\end{abstract}

\begin{abstract}
Coins counterfeitings in convents of Cordoba in 1661

The present study is based on several examples of billon coins counterfeiting in different religious convents of Córoba in the last years of reign of Philippe IV. The money is the centre of this article and it allows to examine throughly an aspect of the life of religious men and the social, economic and jurisdictional situation that leads them to counterfeit money, supported by members of civil society.
\end{abstract}

La investigación numismática segán la metodología moderna permite la aproximación a diversos aspectos históricos que van mucho más allá de la mera descripción, catalogación y análisis intrínseco y extrínseco de monedas. Siguiendo esa línea, el presente artículo abordara temas que tienen profunda relación, no solo con la Numismática, sino también con la historia religiosa,

Sobre economía Eclesiástica Hispania Sacra 49 (1997) 
política, social y legislativa. En efecto, un caso concreto de falsificación de moneda a finales del reinado de Felipe IV nos pone en contacto con la realidad numismática del Reino de Castilla en esos años, con la situación de unos religiosos que ejercieron la falsificación de moneda posibilitados por las condiciones económicas, sociales y monetarias, coordinados en su "trabajo" con otros grupos sociales, y con la existencia de unos cuerpos legislativos que, no solo permitieron, sino que favorecieron la comisión del delito al amparo de los muros de los conventos, al gozar el Clero de un fuero especial y privilegiado.

Es la moneda el eje del presente trabajo. No en vano la política monetaria seguida lo largo del siglo XVII tuvo una incidencia histórica que sobrepaś con mucho el marco económico en el que la moneda nace y al que la moneda sirve. El impacto provocado por los avatares monetarios del siglo del Barroco alcanza no únicamente a la situación financiera y hacendística de la Monarquía, sino también a la política y militar. Afectó igualmente de forma clara al desarrollo económico de Castilla, constituyendo uno de los factores esenciales para la comprensión de la crítica situación vivida durante la mayor parte de estos años; asimismo tuvo una notoria incidencia social, fomentando la formación de grupos que se beneficiaron de la penuria de otros, buscando el lucro personal a costa de sus conciudadanos.

Directamente relacionado con la última afirmación se halla el tema de la falsificación, uno de los peores males sufridos por el numerario del momento. Un caso concreto de este delito, el acaecido en diversos conventos cordobeses en 1661, conservado en el legajo 51.359, $\mathrm{n}^{\circ} 47$, del Archivo Histórico Nacional $^{1}$, constituye un magnífico ejemplo de este hecho que servirá para penetrar en el conocimiento de una de las actividades cotidianas realizadas en los conventos castellanos en diversos momentos del siglo XVII. Ensayo relacionado con la historia religiosa entrelazado con la falsificación de moneda, sus causas y sus consecuencias.

Evidentemente el caso cordobés no fue un hecho aislado. Al contrario, falsificar moneda fue algo habitual en la Castilla del siglo XVII. Sirvan de prueba las constantes alusiones halladas al respecto en la documentación oficial procedente de los Consejos del Rey, especialmente en la expedida por los de Castilla y Hacienda, aunque también por el de Estado debido a la labor de contrabando monetario ejercida por los extranjeros. De igual modo, la legislación nacida como consecuencia de esta realidad es abundante, lo cual refleja la preocupación sentida por los gobernantes, forzados a recurrir a la promulgación de leyes para intentar acabar con el delito.

1 A este legajo y expediente me remito en todas aquellas referencias documentales que no vayan acompafiadas de su correspondiente cita.

Sobre economía Eclesiástica

Hispaniz Sacra 49 (1997) 
La falsificación de moneda, aunque conocida en prácticamente todos los momentos de la Historia desde que comenzara a ser acuñada en el Mundo Egeo a finales del siglo VII a.C., se convirtió en un grave problema para la Monarquía Hispánica ya desde los primeros años del siglo XVII. La explicación de tal fenómeno ha de ser buscada en la política inflacionista seguida por los monarcas Habsburgo desde que Felipe II decidiera el 31 de diciembre de 1596 batir moneda de vellón sin liga de plata, al amparo de Ja perfección de la nueva maquinaría instalada en el Ingenio de la Moneda de Segovia, pensando que tal tecnología evitaría la falsificación, según reza la Real Cédula en la que se ordenaba la reforma del numerario de vellón. Ni los molinos de agua de la ceca segoviana, ni los desvelos de los sucesores de Felipe II pudieron evitar que la considerable diferencia entre los valores intrínseco y extrínseco de la moneda, lo que costaba el metal unido al proceso de fabricación y lo que luego valía oficialmente en el mercado, fomentara la actividad falsificadora por parte tanto de castellanos como de extranjeros.

Testimonios de la creciente importancia del problema abundan ya en los primeros años del siglo XVII. Los perjuicios causados fueron varios y todos igualmente graves. En primer lugar, atentaba contra el monopolio emisor de la Corona y menoscababa su prestigio. Además, incrementaba notablemente el volumen de moneda de vellón en el mercado, hecho que contribuía al descrédito de este tipo de numerario y a su minusvaloración con respecto a la plata. Por ultimo, el lucro que permitía a los falsificadores extranjeros al fabricarla servía para que estos emplearan las ganancias logradas en la extracción del metal precioso que tanto escaseaba en el tránsito comercial castellano.

El principal remedio que empleó la Corona en su intento de acabar con tan acuciante problema fue la aplicación de una legislación punitiva. El Derecho Real castellano tardó en tipificar el delito de falsificación de moneda. Fue Enrique III el primer monarca en penarlo a través de las leyes, pero lo hizo de un modo relativamente benigno. El primer texto legal que lo castiga de forma severa es la pragmática de Medina del Campo, cuerpo legislativo esencial en la ordenación de los asuntos monetarios en la Edad Modema dado por los Reyes Católicos el 13 de junio de 1497. Fernando e Isabel, ante la evidente experiencia falsificadora que representaba el precedente del reinado de Enrique IV, se preocuparon por legislar contra ese grave problema. En esa línea, estipularon la prohibición de fundir y afinar cualquier tipo de moneda fuera de las Casas de Moneda oficiales por ellos establecidas, dictando pena de muerte para todos aquellos que cometieran tal delito, además de la pérdida de la mitad de sus bienes.

Dicho castigo se mantuvo en el siglo XVII, aunque la Corona, ante la dificil situación fue cargando las tintas sobre la represión, pero sin intentar eliminar la raíz del problema monetario que originaba y permitía la falsificación. Su 
política quedo plasmada en sucesivas pragmáticas que endurecían la persecución legal. En ellas la falsificación de moneda quedó convertida en delito de lesa majestad, reprimiéndola con pena de muerte y perdimiento de bienes y especificando que la sentencia sería ejecutada a fuego. Se señalaba que el castigo debía ser impuesto aún en el caso de no llegarse a cometer el delito, se declaraba infames en dos generaciones a los descendientes del delincuente y no se admitía el eximente de menor de edad. Asimismo, se buscó una mejora en los medios de investigación, llegando incluso a involucrar al Tribunal del Santo Oficio el 30 de enero de 1627 , cuando se hicieron causa privativa de la Inquisición todos aquellos casos de falsificación en los que hubiera intención formal de perjudicar la fe, que, según la citada pragmática, eran los protagonizados por los extranjeros 2 .

También atendía la legislación a los encubridores y colaboradores, para quienes se preveía un correctivo similar al de los ejecutores directos. La razón era que en los casos de falsifícación de moneda estos cooperantes jugaban un papel esencial, pues sin su actuación el falsificador tenía mucho más complicado el lucro, como tendremos ocasión de comprobar al analizar los casos concretos de Córdoba.

Evidentemente el fin perseguido por la legislación anteriormente enunciada era la represión: castigar y dar ejemplo a los demás, y hacerlo atemorizando para evitar que otros cayesen en la tentación de recurrir a un medio relativamente sencillo de obtener saneados ingresos. Dicho remedio fue absolutamente ineficaz. El origen del mal, la mala situación de la moneda y la economía castellanas, se mantuvo y, como dijo el Profesor Tomás y Valiente hablando en general sobre las penas impuestas por el Derecho de la Monarquía, "como las causas sociales que impulsaban a delinquir no se corregían, y como cuando se Ilega a cierto nivel de desesperación el miedo no es freno suficiente, sin contar con que se aprende a sortear el peligro al castigo a fuerza de valor y de ingenio, el miedo a la pena fue muchas veces ineficaz"3.

Si el problema había sido sentido a lo Jargo de casi todo el siglo, su máxima intensidad se alcanzó entre 1661 y 1664, coincidiendo con las últimas emisiones de vellón realizadas durante el reinado de Felipe IV. Una vez firmada la paz de los Pirineos y alcanzado el acuerdo con Francia, parecía que la situación internacional permitiría la rehabilitación del numerario castellano o, al menos, que su situación no continuara empeorando. Nada más lejos de la realidad. Libre de los compromisos militares en el norte de Europa, el Rey vio el camino abierto para intentar sofocar la secesión portuguesa. El único medio de

\footnotetext{
2 B.N., Mss. 935, fol. 208.

3 TOMAS Y VALIENTE, F. El Derecho penal de la Monarquta Absoluta (siglos XVI+XVIHXVII), Madrid, Tecnos, 1969, pág. 357.
}

Sobre economia Eclesiastica

Hispania Sacra 49 (1997) 
financiar la consiguiente campaña fue una alteración de la moneda que supuso el nacimiento de un nuevo tipo monetario de vellón, caracterizado por la presencia del busto del Monarca en el anverso en todas las piezas y en el reverso un escudo con todas las armas reales, uno con las de Castilla-León, un castillo o un león, respectivamente y dependiendo del valor de la moneda (ver figs. 1 y 2). El nuevo numerario se caracterizó por contar con 20 granos de plata $(6,94 \%)$ y una talla de 816 maravedíes en marco, en piezas de 16 (4,50 grs.), 8 (2,25 grs.), 4 (1,12 grs.) y 2 (0,56 grs.) maravedíes.

Esta especie monetaria fue una de las más falsificadas de la historia de la Numismática debido a las grandes ganancias que propiciaba su emisión, nada menos que un $62 \% 4$, lucro económico que, como es natural, aumentaba al eliminar la liga oficial de plata o al alterar el peso estipulado en la ley de emisión. El mejor testimonio de la masiva falsificación sufrida por este tipo de moneda es la política adoptada por la Corona en relación con ella. En un primer momento comenzó siendo acuñada en todas las cecas del Reino, siguiendo los tradicionales procedimientos técnicos, el martillo y el molino instalado en el Ingenio de Segovia. Como es lógico, el fraude afectó especialmente a la fabricada a martillo, mucho más tosca y sencilla de contrahacer, lo cual condujo a las autoridades a prohibir el 30 de octubre de $1661^{5}$ la circulación de las piezas batiđas siguiendo dicha técnica, siendo a partir de este momento el molino el único procedimiento empleado en su fabricación. Esta decisión tiene gran importancia en la historia de la moneda castellana, pues supuso la instalación de molinos en las diferentes cecas de la geografía castellana e, incluso, la fundación de otras nuevas, como fueron la de Córdoba o la de la Puerta de Alcalá de Madrid.

Todo fue inútil. Tampoco los adelantos técnicos fueron capaces de sortear la habilidad de los falsificadores, que continuaron ingeniándoselas para mantener tan lucrativa actividad. Un examen de la documentación del Consejo de Castilla permite comprobar como los informes de las autoridades locales dando cuenta de esos hechos delictivos no solo siguieron estando presentes, sino que se multiplicaron. Asimismo las actuales colecciones reunen entre sus fondos un número importante de piezas falsas de época.

Es en este contexto en el que se ubican los hechos acaecidos en Córdoba, que llegaron a conocimiento del Consejo de Castilla a través del corregidor de dicha ciudad, Fernando Manuel de Villafañe. Sucesos de falsificación que de ningún modo pueden ser vistos como algo aislado, sino como reflejo de una realidad profundamente arraigada y enquistada en la vida y en la sociedad castellana. Los informes de Villafañe, fechados entre el 25 de agosto de 1661 y

4 SANTIAGO FernANDEZ, J. de. La pollitica monetaria del siglo XVII en Castilla, Madrid, Universidad Complutense, 1992 (Tesis Doctoral), pág. 324.

5 A.H.N., Reales Cédulas, $n^{\circ} 5.136$. 
el 15 de septiembre del mismo año, constituyen un magnífico testimonio de la situación económico-monetario-social de la Castilla de la época. A través del análisis de este elenco documental obtenemos una valiosa información no solo sobre el mismo hecho de la falsificación a manos de religiosos, con su proceso técnico, sino además de su implantación en el resto de la sociedad, de la preocupación que suscitaba en los gobernantes de Castilla, asi como de los nefastos efectos que provocaba en la economía y el comercio del Reino. Los documentos estudiados dan noticia de la comisión del delito en diversos conventos y edificios de religiosos de la ciudad de Córdoba; estos son los de Nuestra Señora de la Victoria, Santa María de Gracia, San Basilio, la Visitación, San Pablo, el de los frailes basilios establecido en dicha ciudad, una casa de los frailes de la Santísima Trinidad y otra de los carmelitas descalzos. El corregidor da noticia del proceso de investigación seguido hasta llegar a la detención de los culpables, de la situación de los inculpados y de las penas a las que fueron condenados, solicitando además órdenes acerca de cual debía ser su actuación a partir de ese momento.

El análisis de dichos documentos puede ser dividido en varios apartados:

1) El proceso técnico de fabricación de moneda falsa

2) La cuestión jurídico-social subyacente en los informes

3) Los efectos ocasionados por la falsificación en el mercado y la economía castellanos.

Los hechos narrados por Villafañe tuvieron lugar meses antes de publicarse la pragmática de 30 de octubre de 1661 , en la que se prohibía la circulación de las piezas labradas a martillo, ordenando su entrega en un plazo de treinta días, transcurrrido el cual solo podría utilizarse numerario batido a molino. Por ello, el proceso falsificador que en este momento interesa afecto, sin duda, a piezas acuñadas a martillo, aquellas mucho más susceptibles de ser contrahechas sin demasiados problemas por la menor calidad del proceso técnico de fabricación seguido con ellas.

También fue el martillo el medio utilizado para la elaboración de las piezas falsas. Esta afirmación no ofrece ninguna duda. Los instrumentos hallados en diversas estancias del convento de Nuestra Señora de la Victoria en el registro efectuado por el corregidor Villafañe en la madrugada del 18 de agosto de 1661 asi lo demuestran. Tales objetos fueron los siguientes:

Solre economía Eclesiástica Hispania Sacra 49 (1997) 
- En el claustro principal, en una bóveda de entierro, dos bigornias ${ }^{6}$, dos martillos y algunos ochavos batidos y hechos plancha para ser cortados.

- En un hoyo cuadrado situado en una despensa, dos bigornias, dos martillos y algunos ochavos batidos y por batir; en este emplazamiento se hallo también un hoyo que "parecia averse arrancado un cepo de vigornia", según dice el informe.

- En una celda situada en un cuarto que llamaban la enfermería, existente en el segundo claustro del convento, unas piezas blanqueadas y dispuestas ya para ser acufladas, dos troqueles con el escudo con las ammas de la Monarquía grabado y una bigornía con el anverso de las piezas impreso.

- En una celda situada enfrente de la anterior se hallo un hornillo usado como fragua, una chapa de hierro con forma de teja, un banco largo en el que se hallaban tres tijeras, cortaduras resultantes de haber redondeado algunas chapas o cuartos aplanados y batidos, un cepo con una bigonía fija en él, el troquel que le correspondia, un martillo, algunas piezas de moneda gruesa sin batir y un frasco de vidrio con agua fuerte.

- En otra celda próxima, dos esportillas en las que se hallaron cortaduras de cobre, un cuadernillo que contenía la "memoria de la moneda que se entra para sellar y ba prosiguiendo como libro de gasta toda la quenta y razón de lo que cada uno entregava y los nombres de los rreligiosos y de algunos seglares"

- Por último, tres troqueles con las armas abiertas, otros dos por abrirlas, una bigornia, cinco martillos, chapas y monedas blanqueadas para sellar.

Lo tedioso de la enumeración de los objetos hallados en el registro se justifica por ser base esencial para la reconstrucción del proceso técnico y del modo de operar en la elaboración de las piezas falsas. En esta relación, como dice el mismo informe, no se incluyeron todos los objetos que presumiblemente había en el edificio, porque "el convento es mui grande y con facilidad se pudo ocultar mucho y con arta dificultad se alló y descubrió lo rreferido".

Todo proceso de fabricación de moneda comienza por los cospeles? ${ }^{7}$ El método tradicional empleado en las cecas oficiales era la fundición, consistente en verter el metal en estado líquido en unos moldes preparados previamente para que el cospel contara ya con el peso asignado a la futura moneda. No fue éste el sistema utilizado en el suceso de falsificación que nos ocupa y, probablemente, tampoco en la mayoría de los casos que en estos años se dieron. No contradice esta opinión la existencia de un hornillo, que se utilizaba a modo de fragua, entre los objetos hallados en el convento de la Victoria. El and́lisis de la relación antes citada ofrece suficientes datos para suponer que la mayor parte de los cospeles empleados provenían de las antiguas piezas acu-

6 La bigornía era "un género de tenaģas fijas en el vanco de los que labran hierro, que con un husillo o tornillo de hierro aprieta de manera la pieça que en ella se pone, que está fuxa para poderla labrar el oficial a su gusto" (COVARRUBIAS OROZCO, S. Tesoro de la lengua castellana o espafiola, Madrid, 1611).

7 El cospel es el flan métalico de la moneda, ayuno de tipos y leyendas, pero ya con el peso y la aleación estipulados en la ley de emision. 
nadas antes de 1626 y todavía circulantes en el mercado castellano. Las afirmaciones al respecto son varias. El informe de Villafañe alude de forma repetida a ochavos batidos y hechos plancha para ser cortados, a cortaduras resultantes de haber redondeado chapas o cuartos aplanados y batidos, a ochavos por batir y a piezas de moneda gruesa sin batir.

Las citadas expresiones son suficientemente explícitas para afirmar que los cospeles, en su gran mayoría, se obtenían mediante la utilización de la antigua moneda llamada gruesa. La pieza de vellón de mayor valor después de la deflación del 6 de mayo de 1659 era el ochavo (2 maravedíes), cuyo peso térico eran 6,57 grs. La nueva moneda que Felipe IV había ordenado fabricar el 29 de octubre de 1660 , y a la que afectó masivamente la falsificacion, tenía una talla de 816 piezas en marco, de Io que resulta un peso de 4,5 grs. para las de 16 maravedies y de 2,25 grs. para las de 8. A los falsificadores les bastaba con proveerse de ochavos y dividirlos en dos o cuatro partes para tener cospeles de un peso algo inferior, pero bastante aproximado al de las piezas a las que intentaban imitar8. Una vez realizada esta operación, los falsificadores redondeaban y aplanaban el trozo de cobre hasta darle un tamaño similar al de las piezas originales, de ahí la existencia de tijeras, martillos, bigornías e incluso del pequeño homo a modo de fragua, en el que se calentaría el metal hasta darle la temperatura adecuada para someterle al trabajo antedicho.

A la hora de efectuar su labor, los falsificadores se enfrentaban con un problema, la pátina del numerario a imitar que, no debemos olvidar, contaba con un componente de plata importante, $6,94 \%$, que otorgaba a las piezas una coloración blanquecina, bastante diferente al rojizo cobre de los ochavos. De hecho, uno de los argumentos esgrimidos por don Juan de Gongora, artífice de la nueva emisión, para conseguir la aprobación de su proyecto fue precisamente el tono blanquecino que adquiría la moneda con su componente argénteo, pátina que, según él, ayudaría a protegerla de la falsificación'. Nada más lejos de la realidad. Los falsificadores encontraron un medio para solventar esa dificultad, el empleo del aguafuerte. Este uso explica el hallazgo de un frasco con este elemento químico en el registro efectuado en la Victoria. Su utilización era posterior a la elaboración de los cospeles, los cuales una vez redondeados y aplanados serían blanqueados hasta darles una pátina similar a la de las piezas originales.

Posteriormente se procedia al trabajo de acuñación, a la estampación del busto del Rey en el anverso y las armas de la Monarquía o del Reino de Castilla-Léon en el reverso. En la mayor parte de las cecas este trabajo se efectuaba

8 A.H.N., Consejos, leg. 51359, expte. 48.

- SANTIAGo FernandeZ, Op. cit, pág. 323.

Sobre economia Eclesiástica

Hispania Sacra 49 (1997) 
mediante el empleo del martillo, método tradicional que había nacido con la misma moneda en el Mundo Egeo. Era un sistema sencillo consistente en la utilización de dos cuños o troqueles, uno fijo, encastrado en un yunque o pila, en el cual iba grabado el anverso, y otro móvil, encargado de imprimir el reverso sobre el cospel. Una vez colocado éste entre ambos cuños, el golpeo del martillo sobre el móvil producía la fuerza suficiente para verificar la estampación. No parece que el procedimiento empleado en el caso de falsificación que nos ocupa fuera exactamente igual al descrito. Diversas expresiones utilizadas en la documentación sugieren el empleo de la bigornía. Algunas de estas frases son: "una vigornía ynpressa en ella la efigie", "una vigornia y un truquel que le correspondia" o "tres truqueles con las armas abiertas, otros dos por abrir las armas, una vigornía que les correspondían". De ellas se desprende la utitización de la presión de la bigornía para la estampación del cospel, en lugar del tradicional goipeo a martillo. Esa misma herramienta llevaría labrado el anverso, mientras que para el reverso probablemente se emplearan distintos troqueles.

Una vez analizado el proceso de fabricación cabe la pregunta, ¿por que todos los actos falsificadores de los que informa Villafañe tienen lugar en conventos o en casas de religiosos? La respuesta es sencilla: el fuero privilegiado del que gozaban los eclesiásticos. Dicho fuero suponía una importante protección contra un delito castigado con la máxima pena que contemplaba la legislación castellana. De hecho, no fue éste el único caso conocido de falsificación en conventos religiosos. Es más, la documentación llegada al Consejo de Castilla prestó una especial atención a los conventos a lo largo de casi todo el siglo. De la gravedad del problema jurisdiccional planteado a la Monarquía da cuenta un párrafo contenido en la pragmática de 11 de noviembre de 1651, en la que el Rey cuadruplicaba el valor de toda la moneda de vellón acuñada con posterioridad a 159710: "y por quanto en la ocasión del último resello se experimentaron algunos fraudes (...), previniendo los medios que el Derecho permite en casos semejantes de tanta ofensa para el estado público, contra las personas eclesiásticas y religiosas que delinquieren en qualquiera parte destas cosas, teniendo entendido que en estos delitos no ha de valer ningún fuero privilegiado". La cuestión era antigua, pues años antes, en 1637, el Consejo de Castilla habia advertido el problema, solicitado a las autoridades religiosas que tomasen cartas en el asunto e incluso amenazado a estas de proceder el mismo Consejo contra los religiosos falsificadores:

"El Consejo tiene muchas noticias del daño que en esta materia haçen las personas ecclesiásticas y religiosas. Pareçe que convendría que se pidiesen çensuras a el Nuncio contra los exemptos y que los obispos las publiquen en sus obispados contra el clero y

10 A.H.N., Osuna, leg. 2269, expte. 45.

Sobre econonía Eclesiastica Hispania Sacra 49 (1997) 
que se advieria a los superiores de las religiones que con todo desbelo prohiban este abuso, y no lo castigando estos superiores se verá en el Consejo lo que podrá haçer y si se podría extender esta materia a desnaturalifarlos y pribarlos de las temporalidades o poner otras penas según la calidad del exceso"."

Era precisamente este uno de los grandes problemas con los que se enfrentaba el ejercicio de la justicia en Castilla, la complejísima red de jurisdicciones: la jurisđicción real ordinaria, la eclesiástica ordinaria, la del Santo Oficio de la Inquisición, la militar, la señorial, la del Consejo de Ordenes, la del de Hacienda... Problema jurisdiccional en este caso perfectamente interrelacionado con la cuestión monetaria y que evidentemente complicaba mucho la resolución del problema, pues las disquisiciones entre los distintos tribunales entorpecían la administración de justicia, al suponer una serie interminable de cuestiones dilatorias de competencia, y formentaba la comisión del delito. En más de un caso la materia principal quedó olvidada tras el prurito de unos y otros organismos por proteger a los suyos de todo trance ${ }^{12}$.

La cuestión aludida queda perfectamente reflejada en los documentos objeto del presente estudio. Como consecuencia del informe de Villafañe, el Consejo de Castilla envió un escrito al general de la Orden de San Francisco de Paula, a la que pertenecían los religiosos del convento de la Victoria, ordenando que castigara el delito, advirtiéndole que de no efectuarlo asi sería el mismo Consejo el que lo haría. Asimismo, se mandaron cartas a todos los obispos y superiores de las Ordenes para que pusieran todo su cuidado en evitar la comisión de desmanes similares. La preocupación de los gobernantes era lógica, se trataba de evitar un delito cada vez más extendido y que suponía un claro menoscabo de los ingresos regios y del mismo prestigio del Monarca. La necesidad de un castigo ejemplificador está presente en los textos, "que se de exemplo público y quede escarmiento general deste delito" decían y pedían los consejeros de Castilla.

No fueron religiosos todos los implicados en el delito. En el mismo convento de la Victoria fueron hallados tres seglares, asi como en el resto de procesos e investigaciones llevados a cabo por Villafane se vieron envueltos otros personajes alejados del estado clerical. El tratamiento dado a unos y a otros, religiosos y seglares, refleja de forma clara el fuero privilegiado de los primeros. Conocemos las sentencias dadas por el general de Ia orden de San Francisco de Paula a los frailes implicados en la falsificación de la Victoria:

11 A.H.N, Consejos, leg. 51359, expte. 22.

12 Un análisis profundo de estos temas en TOMAS Y VALIENTE, Op. cis, pags. 187-188.

Sobre economía Eclesiástica Hispania Sacra 49 (1997) 
“-Al Padre fray Juan Moreno, lector jubilado y corrector de dicho convento, privación de officio y de voz activa y passiva perpetuamente y desterrado de todos los conventos de este reyno de Córdova perpetuamente y de prisión y reclusión dos años en el convento que por nuestro Padre general le fuere asignado.

- A Fray Pedro de Armería, religioso lego, fugitivo y rebelde, seis años de galeras a remo sin sueldo.

- Al Padre fray Andrés de Segura, sacerdote y sacristón de dicho convento, privación perpetua de voz activa y passiva y desterrado perpetuamente de los Reynos de Castilla y seis años de cárcel en el Real Convento de San Sebastian de Valencia.

- A Fray Francisco Molina consta diez años de privaçión de ser ordenado y seis años de reclusión en un convento que le fuere asignado para el serbicio de la coçina.

- Al Padre Manuel de Avila, predicador y maestro de nobiçios, privaçión perpetua de el officio de maestro y de tres años de voz activa y passiva.

- A los padres Fray Francisco y Agnaio, predicador, Fray Alonso Criado, Fray Juan Galves, Fray Juan Franco de Pedrahita, lector jubilado, Fray Joseph Bueno, predicador, Fray Juan Ciracho, lector de prima, 'Fray Diego Carmona, Fray Thomás Delgado, Fray Francisco Pacheco, lector de Vísperas, Fray Joseph de Riera, predicador, Fray Alonso de Herrera, Fray Juan Naranjo, Fray Alonso Montero, Fray Sebastián de la Rosa, Fray Antonio Palacios y Fray Alonso de Montero privafión de voz activa y passiva por tres aflos.

- A Fray Francisco Faxardo y Fray Antonio de Arreyo, coristas, privación de ser ordenados por seis años."

No parecen ser castigos demasiado severos para un delito tan grave que en la legislación ordinaria conllevaba pena de muerte. La levedad de la condena se manifiesta de forma clara al ser comparada con la aplicada a los seglares detenidos, los cuales recibieron pena capital, exigida por el Rey en la respuesta dada a la consulta efectuada por su Consejo, "hecho menos que juntamente no se me diga haver imbiado orden al corregidor de Córdova para que prozeda contra los seglares conforme a justiçia y assi comvendrá que si ya no estuviere executado se le imbie la orden tanto a él como a las demás justicias de el Reyno, encargándoles que velen mucho sobre esta materia y que donde huviere sospecha de este delito lo averiguen y castiguen en conformidad de lo que disponen las leyes".

También en el proceso penal seguido por el corregidor se evidencia el fuero privilegiado del Clero. Todo el andamiaje legal de la Monarquía estaba entramado en orden a la consecución de la prueba perfecta y esta no era otra que la confesión del acusado. El medio de obtenerla fue la tortura en el caso de los seglares, nunca en el de los religiosos. La tortura como medio de provocar la confesión era pieza esencial del proceso y como tal fue aplicada en este suceso concreto de falsificación, obteniendo los fines perseguidos, pues todos los acusados reconocieron su culpa. 
Todos estos privilegios con que contaban los religiosos sirven para explicar y comprender ese fenómeno que tan ajeno parece a la vida conventual como fue la falsificación de moneda. Actividad unida a los rezos y oficios que sirvió para lucrar las bolsas de los clerigos castellanos a lo largo del siglo XVII.

La presencia de seglares en los conventos o en colaboración con los religiosos plantea un tema distinto del penal, aunque de similar interés. La falsificación de moneda era algo perfectamente enraizado en la sociedad castellana. Las redes de falsificadores estaban bien organizadas y se extendian entre diversos grupos sociales. Junto a los miembros inculpados del estado clerical, el proceso seguido por Villafañe cíta otros nombres, miembros todos de la sociedad civil, incluso dos de los acusados confesaron ser soldados al servicio del Rey. El procurador de Córdoba informó de tres causas. En relación con la primera, citó a Mełchor Blanco, quien confesó haber sellado moneda con Lorenzo del Pino, fabricante de troqueles y un martillo, Juan Francisco, cuchillero, acusado de haber elaborado tijeras y cortado cobre, Luis de Molina, herrero, Pascual Sánchez, encargado de abrir los cuños, Diego de Arroyo, herrero que batía ochavos, Alonso de la Rosa, que entraba el dinero, Ignacio de Morales, alcabucero, y Antonio Cos de Laguna, todos compañeros en el delito. La actuación de estos tuvo lugar en varios puntos: en el convento de Santa María de Gracia, en el campo en una casa o heredad de los frailes de la Santísima Trinidad y en el convento de San Basilio. En la segunda, acaecida en la casería de San Pablo, se detuvo a Lorenzo Varrán, que murió víctima del tormento, a Juan García, a Alonso Esteban, a Alonso García y a Domingo Rodríguez, junto al clérigo sacerdote Diego de Roa Melgarejo, culpándose también a un fraile lego que huyó. En la causa del convento de la Victoria, además de a los frailes, hallo culpables a Alonso García, Juan de Alvín, ambos soldados, y Diego Rodríguez, los cuales reconocieron haber cortado moneda, junto a los que hay que citar a Pedro González, herrero, a quien se trajo preso de Almadén.

Los personajes aludidos son los principales, pero en el informe de Villafañe se especifica que existieron muchos cómplices más. En este documento destacan diversos puntos que llaman la atención. En primer lugar, la mayoría de los detenidos están relacionados con la fábrica de los instrumentos necesarios para llevar a cabo la falsificación, herreros, cuchilleros, etc. además, todos los procesos de los que informa el corregidor tienen como punto final un convento, la falsificación fue hecha en casas de religiosos. De lo anterior se deduce que los miembros del estado clerical fueron un eslabón más, bien es cierto que importante, en la trama falsificadora; no actuaban solos, necesitaban colaboradores integrados en la sociedad civil que les suministraran la materia prima, en este caso los ochavos, las herramientas, la técnica precisa en el proceso de fabricación y la posterior distribución de las piezas falsas en el mercado. Los religiosos aportaban a cam-

Sobre economía Eclesiastica Hispania Sacra 49 (1997) 
bio una supuesta seguridad y protección al efectuarse los trabajos al amparo de los fueros y los muros de los conventos.

La actividad desarrollada se hacía de forma rigurosa, de ningún modo se llevaba a cabo sin orden ni concierto. Asi lo prueba uno de los hallazgos del convento de la Victoria, el libro en el que figuraban las entradas de cobre, con la cuenta y razón de lo que cada uno entregaba, la relación de gastos, asi como las personas participantes en el negocio. Este documento permite deducir una perfecta organización, que controlaba todo el trabajo falsificador, y en muchos aspectos similar a la existente en una ceca oficial.

Expuesto todo lo anterior, se puede afirmar que la falsificación de moneda se convirtió en uno más de los numerosos recursos a los que recurrieron distintas capas de la sociedad castellana para combatir la crisis económica en el siglo de la picaresca; todo ingenio era poco para obtener maravedíes que ayudasen a la subsistencia diaria. Es cierto que el clerical era uno de los estamentos privilegiados y que contaba con saneados ingresos, pero no lo es menos que las rentas eclesiásticas se distribuían de forma pésima, con una clara distinción entre conventos ricos y pobres. Igualmente quizá sea importante destacar que los efectivos integrantes del Clero procedían de toda la escala social, no era un bloque cerrado ni exclusivista; muchos de ellos tomaron los hábitos con el único fin de gozar de los privilegios y de escapar de los "males del siglo", pues entrar en la Iglesia significaba verse libre de la fiscalidad, del hambre y de las levas.

Un último aspecto que no debe ser pasado por alto es el tocante al efecto que la falsificación producía en el mercado y en la sociedad castellana. Sus graves consecuencias explican la rigurosa reacción de las autoridades y el cuidado que en todo momento se ponía en evitar la comisión de este delito. Es cierto que es un tema conocido y que ya tuve ocasión de estudiar en otro lugar $^{\text {t3 }}$, pero no lo es menos que la aparición de nueva documentación que permite corroborar opiniones ya vertidas no debe ser pasada por alto y aún menos en un trabajo dedicado de forma específica a la falsificación.

La masiva producción de moneda llevada a cabo mediante tramas falsificadoras como la descrita en páginas anteriores produjo efectos muy negativos en el comercio y en la actividad financiera de la Corona. Las piezas contrahechas se mezclaron rápidamente con las fabricadas de forma oficial en las cecas del Rey. Esa unión de numerario auténtico y falso fue nefasta, pues pronto los expertos y las personas acostumbradas al manejo de grandes cantidades, hombres de negocios, depositarios, receptores, percibieron el fraude y rehusaron la admisión de estas piezas. El efecto se traslado a los hombres del campo y propietarios de pequeños comercios en las ciudades, pues recibiendo ellos mone-

13 SANTIAgo Fernandez, Op. cit, págs. 327-329.

Sobre economía Eclesiástica Hispania Sacra 49 (1997) 
das falsas, luego no conseguían que les fuesen aceptadas a la hora de efectuar sus pagos. El resultado fue el rechazo de toda moneda, falsa o auténtica, que llegara a sus manos, por ser incapaces de distinguirlas. El numerario falso contaminó al auténtico y como resultado de ello la nueva moneda ligada, en la que la Corona había puesto tantas esperanzas de financiación, provocó un auténtico colapso mercantil, paralizando el comercio y ocasionando problemas de abastecimiento en distintas ciudades. Es el caso de Córdoba, que documenta Villafañe, pero también el de Granada, donde las autoridades se vieron obligadas a instalar palenques para distribuir pan y calmar los ánimos de la población, el de Sevilla o el de Osuna, por citar algunos de los casos más significativos entre los ofrecidos por la documentación ${ }^{14}$.

La solución era complicada. El corregidor planteó el problema de forma perfecta, pues, como él decía, autorizar la circulación de las piezas falsas, ya totalmente integradas y mezcladas con el numerario auténtico, era tanto como dar pie a que continuase la actividad falsificadora; se daba valor a lo que legalmente no debería tenerlo y, lo que era más importante y peligroso, se alentaría a los que la falseaban con la facilidad de la distribución al tener fácil salida el producto fraudulento. Si por el contrario se prohibía la circulación de ese numerario "será suma confussión y se suçitarán ynfinitos pleitos, todo será enbarazoso y para conoçerla y distinguirla no abrá tiempo, ni plateros, ni ensayadores podrán jurar yndibidualmente sin hazer los ensayes y lo que peor es que los pobres miserables serán los perdidores assi los de los cortos comerçios y jéneros de poco preçio, tiendas y puestos de menudencias, como los honbres del campo, hornaleros y demás travajadores". El resultado final, de aplicarse esta última solución, sería el rechazo total de todo numerario, tanto el auténtico como el falso, con la consiguiente desaparición de la moneda de menudeo en el mercado castellano, y el inevitable problema de parálisis comercial. Fue este último el arreglo aplicado por los gobernantes y los problemas descritos los ocasionados ${ }^{15}$.

Los párrafos anteriores sirven para comprobar como aspectos monetarios concretos, en este caso la falsificación de moneda, tienen incidencias sociales y jurídicas determinadas, elementos todos los cuales deben ser contemplados y tenidos en cuenta por el historiador de la moneda. Esta visión de la Numismática, mucho más ámplia que la tradicional, es la que he intentado plantear en este artículo, centrándome en la moneda, en concreto en su falsificación y efectos, pero teniendo en cuenta al mismo tiempo otras circunstancias sin las cuales sería difícil dar un por qué a dicha actividad realizada precisamente en el interior de los conventos, temas claramente relacionados con la historia social y la religiosa, pero también con la del Derecho y la de la Economía.

14 A.H.N., Consejos, leg. 51359, expte. 48.

is Ver SaNTIaGo Fernandez, Op. cit, págs. 328-330. 


\section{APENDICE DOCUMENTAL}

1. Informe del corregidor de Córdoba, Femando Manuel de Villafañe, sobre el registro efectuado en el convento de Nuestra Señora de la Victoria en relación con la fabricación de moneda falsa. Córdoba a 18 de agosto de 1661.

A.H.N., Consejos, leg. 51.359 (I), $\mathrm{n}^{\circ} 47$.

(cruz) .

Señor

Continuando el desvelo y cuidado para atajar el daño que caussan los que fabrican y falsean la moneda nueba y poniendo todos los medios posibles para el rremedio, aberiguaçion y castigo de tan gran desorden, aviéndome dado notiçia que en el conbento de Nuestra Sefrora de la Vitoria de la Orden de San Francisco de Paula, que está extramuros de esta ziudad, y q̧ertificado con algunas diligençias extrajudiçiales, me resolví a entrarme en él buscando ocassión para que con maña y secreto se pudiesse lograr el yntento sin escándalo e ynquietud y, puniéndolo en execuçión, ayer a las dos de la mañana salí acompañado de mis dos alcaldes maiores y de todos los ministros y algunos escrivanos y con todo silençio me arrimé a dicho combento dividiendo la gente haçia las çercas de la puerta y las partes que ubjesse huyda al campo y pusse tres ministros con todo secreto junto a la portería y otros tres a la puerta de la yglessia, para que en abriendo qualquiera de ellas se detubiesse al portero y se me diesse avisso, quedando cerca lo más encubierto que pude con el Alcalde de la Justicia y algunos ministros. Y abriendo la primera la portería de los carros, que está zerca de la regular, se executó como tenía pensado y entrando de golpe hasta los claustros sin enbaraço alguno por estar los rreligiossos recogidos en sus çeldas, que con el rruydo se començaron a alborotar y a salir de ellas a medio bestir, dessatinados con accidente tan rrepentino y yo les sosegué y dije me llamassen a su prelado, que benía a negoçio mui ynportante y del serviçio de Su Magestad, con que se turbaron y el prelado no pareçio y por los alcaldes mayores y demás ministros seguí vissitando el convento, quedándome yo en el claustro principal con tres o quatro religiossos de los de más autoridad, persuadiéndoles a que ubiesse toda quietud y que, pues no pareçía o no estaba en cassa su prelado, el superior o vicario asistiesse a los alcaldes mayores para que se abriesen las puertas de todas las ofiçinas y demás partes combenientes, estando yo siempre a la mira para que no ubiesse conmoçion. El rreligioso assistió con toda puntualidad y quietud y los demás estubieron con la misma y mucha modestia y templança. Hallosse en el mismo claustro principal en una bobbeda de entierro, esterado el suelo, dos bigornías, dos martillos, algunos ochavos batidos y hechos plancha para cortar.

En una despensa que está a mano đerecha como se entra a la puerta, un boyo cuadrado del alto de un hombre, esterados suelos y paredes, cubierto con esteras y enpaliçada y en él dos

Sobre economia Eclesiástica Hispania Sacra 49 (1997) 
vigornías y dos martillos y algunos ochavos batidos y por batir y un hoyo en medio que parecía averse arrancado un çepo de vigomia.

En el segundo claustro en un cuarto que llaman la enfermería baja, en una çelda de ella se allo un fraile lego que ocultava unas pieças blanqueadas y dispuestas ya para sellar y enprimir las armas y efigie y por la dicha ocultación se passó a mirarle y rregistrarle la perssona y debajo del ávito en un zinto se le allaron dos truqueles o sellos con las amas y una vigornía ynpressa en ella la efigie.

Habriosse otra zelda enfrente desta y se hallo un homillo como fragua y una chapa de yerro en forma de teja y un banco largo, filadas en el tres tigeras de cortar cobre y debajo de ellas, en una estera, cantidad de cortaduras de aver redondeado algunas chapas o quartos aplanados y batidos y un cepo fixa en él una vigomia y un truquel que le correspondía, un martillo y algunas pieças de moneda gruessa por chapar o batir, un frasco de vidrio con aguafuerte y masuras de zinada para blanquear. $Y$ los ministros que estavan en la puerta vieron que hechavan de una çelda dos esportillas en que allaron cortaduras de cobre como las que estavan debajo de las tijeras y subiendo a la dicha zelda que hera la del sacristán, en un cajón de un pie de escritorio, se allo un cuadernillo de quartilla que en la primera oja diçe memoria de la moneda que se entra para sellar y ba prosiguiendo como libro de gasta toda la quenta y maçon de lo que cada uno entregava y los nombres de los rreligiosos y de algunos seglares. Y discurriendo por las demás partes, çeldas y sitios del combento se allaron sobre la bóbeda alta de una capilla tres hombres en calçones blancos y camisa y en el dicho sitio y diferentes partes de el tres trugeles con las armas abiertas, otros dos por abrir las armas, una bigornía que les correspondian, çinco martillos, cantidad de chapas y otras pieças de moneda blanqueadas para sellar. No se pudo hallar más, aunque se buscó con arto cuydado, pero el combento es mui grande y con facilidad se pudo ocultar mucho y con arta dificultad se allo y descubrió lo rreferido, sacarónse todos los dichos ynstrumentos y se lievaron pressos los dichos hombres que el uno dicen es alférez y el otro sargento, están en la cárçel apartados y ençerrados para tomarles sus declaraçiones y proseguir en las diligençias, que por no estar los autos en forma no enbio estimaçión en relaçión hasta la estafeta que biene con todo lo que ubiere resultado de las declaraçiones y las demás diligençias. Ase dado quenta a su general y diçen estará aqui mui presto, con que de todo lo que obrare y rresoluçión que tomare daré quenta a Vuestra Magestad, cuya Católica y real persona guarde Nuestro Seffor, como la Christiandad y los vasallos de Vuestra Majestad hemos menester. Agosto 18 de 1661

Femando Manuel de Villafañe.

2. Informe del corregidor de Córdoba, Fernando Manuel de Villafañe, sobre tres causas de falsificación de moneda en dichra ciudad. En Córdoba, a 15 de septiembre de 1661.

A.H.N., Consejos, leg. 51.359 (I), $\mathrm{n}^{\circ} 47$.

(Cruz)

Ilustrísimo Sefior

Por falta de execución de la Justicia no se ha podido antes proseguir en las causas de la moneda, trúxose de fuero y doy quenta a Vuestra Scñoría de el estado en que están.

Sobre economía Eclesiástica

Hispania Sacra 49 (1997) 
En la primera causa en que se començó a proceder resultaron reos principales Melchor Blanco y Lorenço de el Pino. Estos, aunque convictos por muchas circunstancias, han estado negativos, con que se les ha dado tormento y con el quedan convictos y confesos en el delito de aver fabricado monedas, hecho yerros y otros instrumentos para el dicho efecto, el dicho Lo. renço del Pino. Ay presos en esta causa otros que son Joan Francisco, cuchillero, por aver hecho unas tijeras para cortar cobre y otro, Baltasar Lorenco, oficial del dicho Lorenço del Pino, y Pedro Jorge, estos van con los tormentos y con lo que los otros declaran, purgando los indicios y quedan libres. De las declaraciones de estos culpados, convictos y confiesos, resultan reos Luys de Molina, herrero, Pasqual Sánchez, que abria los sellos, Diego de Arroyo, que vatía ochavos, tanbién herreros, y Alonso de la Rosa, que entraba el dinero, estos fabricaban en el convento đe Santa María de Gracia. También resultan reos (ausentes) en abrir sellos Ignacio de Morales, alcabucero, y un compañero clérigo que no se sabe el nombre. Asimismo ausentes, como los demás referidos, son reos principales dos hermanos llamados Alonso, y acúsalos del Pino, y Antonio Cos de Laguna, aladrero, todos compañeros en el delito. Mas resultan reos en este delito un frayle lego de Santo Domingo, en el convento de los Mártires de esta ciudad, llamado fray Xenaro, otro frayle lego trinitario que no se sabe su nombre y consta averse fabricado en el campo en una casa o heredad de los frayles de la Santisima Trinidad. $Y$ asimismo en el convento de San Basilio de esta ciudad, siendo el prior y el predicador de dicho convento quien fomentaba y aviaba la fábrica, ayudando otros frayles en diferentes exercicios de ella, esta causa se concluyrá y sentenciará en toda brevedad.

La segunda causa fue la aprehensión que se hiço en el campo, en la casería de Sar Pablo. En esta sucedió la muerte del reo, quitándole del tormento, llamabase Lorenço Varran. Los otros quatro, Joan García, Alonso Esteban, Alonso García y Domingo Rodríguez, quedaron tales de lo que tomaron para prepararse que no ha sido posible dar con ellos por estar con calentura y muy débiles y a el más fuerte a el parecer en el sugeto, solo de ponerle la cincha sin otra diligencia por poco sucede lo mismo que con el primero, con que ha obligado, por la poca seguridad que ay en la cárcel y descuydo del alcayde, a dar los tormentos en mi cassa, con bastante mortificación y descomodidad. En esta aprehensión se cogió un clérido saceróote, llamado Diego de Roa Melgarejo, que tiene preso el Señor Obispo, y el frayle lego casero huyo, con que aunque estos reos están para hacer con ellos diligencias está suspensa esta causa.

La tercera fue la aprehensión en el convento de la Vittoria y en ella se aprehendieron tres hombres llamados Alonso García y Joan de Alvin, que dicen ser soldados, y Diego Rodríguez, este está convicto y confieso; tanbién se trujo preso de el Almadén a Pablo González, herrero, que es de los principales culpados. Están sentenciados a tormento que se yra executando desde esta noche.

Otros muchos reos ay ausentes y se yrán las dudas descubriendo y parece precisso a los convictos y confiesos condenarlos en la pena ordinaria y executar, sin embargo suplico a Vuestra Señoría llustrísima se sirva de que se me ordene lo que debo hacer porque como en otras partes no se han executado y la suspension de Sevilla, no querria exceder. $Y$ de todo yre dando quenta a Vuestra Señoría liustrísima a quien guarde Nuestro Señor como se lo supplico y todos hemos menester. Cordova y septiembre 15 de 1661.

Fernando Manuel de Villafafie. 

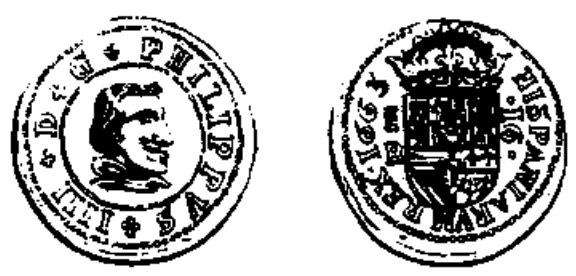

Fig. 1: Pieza de dieciseis maravedies
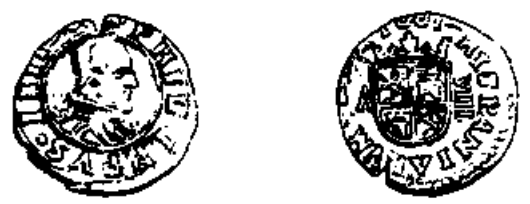

Fig. 2: Pieza de ocho maravedíes

Ambas figuras han sido tomadas de HEISS, A. Descripción general de las monedas hispanocristianas desde la invasión de los árabes, Madrid, 1865.

Sobre economía Eclesiástica

Hispania Sacra 49 (1997) 